\title{
COMPARISON OF EPIDURAL-FENTANYL AND LEVOBUPIVACAINE WITH FENTANYL AND BUPIVACAINE FOR LOWER ABDOMINAL AND LOWER LIMB SURGERIES- A PROSPECTIVE STUDY
}

\author{
Shanta Hungund ${ }^{1}$, Divya A. Hirolli2, Raghavendra Bhosale ${ }^{3}$, Thilakchand K. $R^{4}$ \\ ${ }_{1}^{1}$ Associate Professor, Department of Anaesthesia, KIMS, Hubli, Karnataka. \\ ${ }^{2}$ Senior Resident, Department of Neuroanaesthesia, NIMHANS, Bangalore, Karnataka. \\ ${ }_{3}^{3}$ Assistant Professor, Department of Anaesthesia, KIMS, Hubli, Karnataka. \\ ${ }_{4}^{4}$ Postgraduate Student, Department of Anaesthesia, KIMS, Hubli, Karnataka.
}

\section{BACKGROUND}

ABSTRACT

Bupivacaine is a long-acting amide and is widely used as local anaesthetic for epidural anaesthesia. It has a beneficial ratio of sensory to motor block in epidural anaesthesia. This agent also provides high quality analgesia in the post-operative period. However, bupivacaine-induced cardiotoxicity in patients following accidental intravascular injection limits its use. It also has potential for neurotoxicity. Sudden cardiac deaths and high proportion of maternal deaths are reported. ${ }^{1}$ Therefore, a local anaesthetic which has similar effects as bupivacaine but has less side effects on cardiovascular system is needed. Levobupivacaine is the pure S (-) enantiomer of racemic bupivacaine. It seems to be an alternative safer local anaesthetic agent in epidural anaesthesia. 1

The purpose of this study was to compare levobupivacaine and bupivacaine in epidural with Fentanyl as a common adjuvant for lower abdominal and lower limb surgeries.

\section{MATERIALS AND METHODS}

A prospective, double-blind, randomised controlled study was planned. 80 patients of ASA I and II, physical status aged between 18 - 60 yrs. who underwent elective infraumbilical and lower limb surgery from $1^{\text {st }}$ January 2014 to 31st December 2014, and satisfying all the inclusion criteria were enrolled in the study and were randomly allocated into two groups.

Group F + B (n= 40)= patients received $0.5 \%$ isobaric bupivacaine $13 \mathrm{~mL}$ with fentanyl $100 \mu \mathrm{g}(2 \mathrm{~mL})$ in epidural.

Group $\mathrm{F}+\mathrm{L}(\mathrm{n}=40)=$ patients received $0.5 \%$ isobaric levobupivacaine $13 \mathrm{~mL}$ with fentanyl $100 \mu \mathrm{g}(2 \mathrm{~mL})$ in epidural. The two groups were compared for sensory blockade, motor blockade and the haemodynamic parameters. Group allocated to the patient was revealed at the end of study.

\section{RESULTS}

Mean time taken for complete loss of cutaneous sensation at T10 for F + L group was 4.68 min and F + B group was 6.75 min which was statistically significant, $(\mathrm{p}=0.0001)$. Maximum motor blockade was better with $\mathrm{F}+\mathrm{B}$ group and the mean time for regression to Bromage 1 for $\mathrm{F}+\mathrm{B}$ group was $119.88 \mathrm{~min}$ and $\mathrm{F}+\mathrm{L}$ group was 111.13 showing a prolonged motor blockade with $\mathrm{F}+\mathrm{B}$ group ( $p=0.0037$ ). Haemodynamic parameters were comparable for the two groups.

\section{CONCLUSION}

The onset of sensory blockade was faster with F + L group. F + B group produced denser and prolonged motor blockade. Haemodynamic profile was comparable with the two groups. Levobupivacaine can be a good alternative to bupivacaine, the faster onset of sensory blockade, the smaller rate of motor blockade and the trend towards a smaller duration of motor blockade shows an interesting and potentially useful difference.

\section{KEYWORDS}

Bupivacaine, Levobupivacaine, Fentanyl, Epidural, Motor Blockade.

HOW TO CITE THIS ARTICLE: Hungund S, Hirolli DA, Bhosale R, et al. Comparison of epidural-fentanyl and levobupivacaine with fentanyl and bupivacaine for lower abdominal and lower limb surgeries- a prospective study. J. Evolution Med. Dent. Sci. 2018;7(11):1380-1384, DOI: 10.14260/jemds/2018/314

\section{BACKGROUND}

"Divine is the task to reduce pain" - Hippocrates. Analgesia i.e. the relief of pain is one of the most important components of anaesthesia. There are various ways in which this relief of pain can be given to a patient during and after surgery.

'Financial or Other Competing Interest': None.

Submission 25-01-2018, Peer Review 19-02-2018,

Acceptance 27-02-2018, Published 12-03-2018.

Corresponding Author:

Dr. Shanta Hungund,

H. No. 1, Block Number 10,

GO Quarters, KIMS Campus,

Hubli-580022.

E-mail: shantahungund@gmail.com

DOI: $10.14260 /$ jemds $/ 2018 / 314$

\section{(c) (i) $\$$}

Regional anaesthesia is one such modality to relieve pain. Spinal, epidural and caudal neuraxial blocks result in sympathetic blockade, sensory analgesia or anaesthesia and motor blockade depending on the dose, concentration or volume of local anaesthetic after insertion of a needle in the plane of the neuraxis.

Epidural anaesthesia is used for procedures involving the lower limbs, pelvis, perineum and lower abdomen. It is also possible to perform upper abdominal and thoracic procedures under epidural anaesthesia alone.

The advantage of epidural over spinal anaesthesia is the ability to maintain continuous anaesthesia after placement of an epidural catheter, thus making it suitable for procedures of long duration. Following surgery, lower concentrations of 
anaesthetic drugs can also be introduced to relieve surgical pain.

Bupivacaine, levobupivacaine and ropivacaine provide excellent quality of anaesthesia for neuraxial techniques. Bupivacaine is found in two different enantiomers: levobupivacaine - S (-) and dextrobupivacaine - R (+). Based on studies showing that $S(-)$ enantiomers are less cardiotoxic, their use has been increasing in clinical practice.

Bupivacaine is a long-acting amide and is widely used as local anaesthetic for epidural anaesthesia. This agent also provides high quality analgesia in the post-operative period. Bupivacaine induces cardiotoxicity in patients following accidental intravascular injection. It also has potential for neurotoxicity. Sudden cardiac deaths and high proportion of maternal deaths are reported. ${ }^{1}$

Levobupivacaine shows an extended duration of action, and is frequently used in surgery and obstetrics and postoperative pain management. Pharmacokinetically, LB has been compared to racemic $\mathrm{B}$ alone and $\mathrm{R}+$-bupivacaine alone in healthy volunteers after intravenous injection, epidural administration and brachial plexus block. At equal dosing, there are no differences in the pharmacokinetic parameters between these two agents. 2,3

However, some studies have shown that depending on the dose used for LB, B may produce a significantly longer duration of sensory block. ${ }^{4}$

On the other hand, although B is generally well tolerated in everyday clinical practice, this molecule shows a cardiac toxicity significantly higher than other local anaesthetics such as lidocaine. This increased toxicity translates into some additional risk for fatal accidents due to intravascular injection of the drug or due to rapid absorption into the blood stream as in the case of a Bier type block. ${ }^{5}$

Therefore, a local anaesthetic which has similar effects as bupivacaine but has less side effects on cardiovascular system is needed. Bupivacaine is used as a racemic mixture of equimolar amounts of $\mathrm{R}(+)$ Dextrobupivacaine and S (-) Levobupivacaine. R (+) Dextrobupivacaine is found more toxic to both the central nervous system and the cardiovascular system. Levobupivacaine is the pure $S(-)$ enantiomer of racemic bupivacaine. It seems to be an alternative safer local anaesthetic.

Narcotic analgesics are commonly used as adjuncts to local anaesthetics (LA) in epidural anaesthesia. They hasten the onset, improve the quality of the block as well as prolong the duration of analgesia. Fentanyl is a highly lipid-soluble, strong $\mu$-receptor agonist and phenylpiperidine derivative with a rapid onset and short duration of action. The rationale for adding fentanyl with the two drugs is that the local anaesthetic act at the nerve axon and the opioid at the spinal cord receptor to eliminate pain via a combined and possibly synergistic mechanism. Use of fentanyl is also known to reduce the minimum local analgesic concentration of bupivacaine and levobupivacaine, thereby reducing their side effects. ${ }^{6}$ This study aimed at comparing racemic bupivacaine and levobupivacaine in epidural anaesthesia for lower limb and lower abdominal surgeries using fentanyl as a common adjuvant.

\section{Aims and Objectives}

To compare the following factors in two groups- $13 \mathrm{~mL}$ of $0.5 \%$ Levobupivacaine (isobaric) and $2 \mathrm{~mL}$ of fentanyl with $13 \mathrm{~mL} \mathrm{0.5 \%} \mathrm{Bupivacaine} \mathrm{(isobaric)} \mathrm{and} 2 \mathrm{~mL}$ of fentanyl for epidural anaesthesia in lower limb and lower abdominal surgeries in adults aged 18 to 60 years with respect to-

- Onset of sensory block,

- Highest level of sensory block,

- Duration of sensory blockade,

- Onset and duration of motor blockade (Using Modified Bromage scale),

- $\quad$ Maximum motor blockade.

\section{MATERIALS AND METHODS}

A prospective, double-blind, randomised controlled study was planned. 80 patients of ASA I and II physical status aged between 18 - 60 yrs. were recruited after the Institutional Ethical Committee clearance. The study period was from $1^{\text {st }}$ January 2014 to $31^{\text {st }}$ December 2014. Patients enrolled after having satisfied the inclusion criteria and were posted for elective infraumbilical and lower limb surgeries. Sample size was taken conveniently. Patients were randomised using computerised randomisation table and were allocated into two groups of 40 each. Group F + B received $0.5 \%$ isobaric bupivacaine $13 \mathrm{~mL}$ with fentanyl $100 \mu \mathrm{g}(2 \mathrm{~mL})$ in epidural route. Group F $+\mathrm{L}$ patients received $0.5 \%$ isobaric levobupivacaine $13 \mathrm{~mL}$ with fentanyl $100 \mu \mathrm{g}(2 \mathrm{~mL})$ in epidural route. The two groups were compared with respect to sensory blockade, motor blockade and the haemodynamic parameters.

\section{Inclusion Criteria}

Males and females in age group 18 - 60 years, ASA grade I and II; Patients scheduled for lower abdominal and lower limb surgeries where epidural anaesthesia would be indicated; Patients giving written and valid consent were included in the study.

\section{Exclusion Criteria}

Allergy or hypersensitivity to the study drug; Severe renal, hepatic, cardiac or respiratory impairment; Previous history of neurological, neuromuscular or psychiatric disorders including seizures; Previous history of haematological disorders including coagulation abnormalities.

Written valid and informed consent was taken. The study drug was given to the investigator by an anaesthesiologist unrelated to the study and the drug was not revealed to both the investigator and the patient.

All the patients undergoing the study were premedicated with tablet Diazepam $10 \mathrm{mg}$ and tablet Ranitidine $150 \mathrm{mg}$ on previous night of surgery. Patients were hydrated with $10 \mathrm{~mL} / \mathrm{kg}$ Ringer's lactate intravenously before the procedure.

Study population was randomly divided into 2 groups with 40 patients in each group, one group received $13 \mathrm{~mL}$ of $0.5 \%$ bupivacaine with $2 \mathrm{~mL}$ of $100 \mathrm{mcg}$ of fentanyl (total volume- $15 \mathrm{~mL}$ ) and named group ' $\mathrm{F}+\mathrm{B}$.' The other group received $13 \mathrm{~mL}$ of $0.5 \%$ levobupivacaine with $2 \mathrm{~mL}$ of 100 mcg of fentanyl (total volume- $15 \mathrm{~mL}$ ) and named group $\mathrm{F}+\mathrm{L}$. 
Monitoring included pulse oximetry, electrocardiograph (ECG) and non-invasive blood pressure (NIBP).

Under aseptic precautions, an 18-G Tuohy's epidural needle was introduced into L1 - L2 epidural space using loss of resistance to air technique. Epidural catheter was inserted $4 \mathrm{~cm}$ into the epidural space and $3 \mathrm{~mL}$ of $2 \%$ lignocaine with adrenaline was given as a test dose. Continuous cardiopulmonary monitoring was done and the study drug was injected into the epidural space. The time of administration of the study drug was considered as zero time to assess the duration of blockade.

Baseline values of pulse rate, blood pressure and saturation were recorded and for every 5 minutes until 30 minutes after epidural drug administration and every 15 minutes thereafter for the next 300 minutes.

Sensory blockade was assessed using pin-prick method till the complete loss of cutaneous sensation at T10. Onset is defined as time interval between the end of administration of the anaesthetic drug and the onset of cutaneous analgesia at T10. Highest level of sensory blockade as well duration of sensory block was documented. Motor blockade was tested using Modified Bromage scale. Time of onset, maximum motor blockade and the duration of motor blockade was assessed.

\section{Modified Bromage Scale}

- $0=$ no block

- $1=$ inability to raise extended leg

- $2=$ inability to flex the knee

- $3=$ inability to flex ankle and foot

\section{Statistical Analysis}

Statistical analysis was done using student's ' $t$ ' test for parametric data and Chi-square test for non-parametric data. The data obtained was subjected to statistical computation using Statistical Package for Social Sciences (SPSS) version 20.0 and value of $\mathrm{p}<0.05$ was considered significant and $\mathrm{p}<$ 0.0001 as highly significant.

\section{RESULTS}

The mean time taken for complete loss of cutaneous sensation at $\mathrm{T} 10$ for $\mathrm{F}+\mathrm{B}$ group is $6.75 \pm 0.95$ minutes and in $\mathrm{F}+\mathrm{L}$ group it is $4.68 \pm 0.83$ minutes. The ' $\mathrm{p}$ ' value being
0.0001 is significant, which means $\mathrm{F}+\mathrm{L}$ group has a faster onset of sensory blockade when compared to $\mathrm{F}+\mathrm{B}$ group.

The time taken for 2 segment regression of sensory blockade is $166.38 \pm 11.93$ for $\mathrm{F}+\mathrm{B}$ group and $166.5 \pm 11.11$ minutes for $\mathrm{F}+\mathrm{L}$ group with a ' $\mathrm{p}$ ' value of 0.96 . Thus, the time taken for 2 segment regression of sensory blockade for the two groups is comparable ( $p>0.05)$.

The time taken for onset of motor blockade with Bromage score 1 for the group $\mathrm{F}+\mathrm{B}$ is $8.48 \pm 0.85$ minutes and for the $\mathrm{F}+\mathrm{L}$ group is $8.5 \pm 0.82$ minutes with a ' $\mathrm{p}$ ' value of 0.89 . Hence, the two groups are comparable in terms of onset of motor blockade.

The duration of motor blockade was estimated by the time taken for regression of Bromage score to 1 and it was seen that the group F $+B$ had a mean duration of $119.88 \pm$ 12.12 minutes and $\mathrm{F}+\mathrm{L}$ group had a mean duration of $111.13 \pm 13.94$ with a 'p' value of 0.003 . Thus, the duration of motor blockade was significantly prolonged for $\mathrm{F}+\mathrm{B}$ group when compared to $\mathrm{F}+\mathrm{L}$ group.

The mean duration of surgery for $\mathrm{F}+\mathrm{B}$ group was 94.88 $\pm 21.59 \mathrm{~min}$ and that of $\mathrm{F}+\mathrm{L}$ group was $87.75 \pm 19.15 \mathrm{~min}$. The two groups were comparable in terms of total duration of surgery ( $p>0.05)$.

31 patients from $\mathrm{F}+\mathrm{B}$ group are ASA 1 and 3 patients are ASA 2; F + L group also has got 31 ASA 1 patients and 3 ASA 2 patients. The two group are comparable in terms of ASA grading with a 'p' value of $1(>0.05)$.

$\mathrm{F}+\mathrm{B}$ group had 3 patients with highest level of sensory blockade as T5, 27 patients with T6, 8 patients with T7 and 2 patients with T8. F + L group had 3 patients with maximum sensory blockade of T5, 25 patients with $\mathrm{T} 6,10$ patients with T7 and 2 patients with T8. The two groups had a 'p' value of 0.96 for comparison of highest level of sensory blockade. Thus, the highest level of sensory blockade was comparable for the two groups ( $p>0.05$ ).

8 patients in $\mathrm{F}+\mathrm{B}$ group had a Bromage score of 2 and 32 patients had a Bromage score of 3 , whereas 35 patients in group F + L had a Bromage score of 2 and 5 patients had a Bromage score of 3 . The ' $p$ ' value being 0.00001 showed that maximum motor blockade achieved was better with $\mathrm{F}+\mathrm{B}$ group when compared to F + L group.

\begin{tabular}{|c|c|c|c|c|c|c|}
\hline \multirow{2}{*}{ Parameters in Minutes } & \multicolumn{2}{|c|}{ Group F + B } & \multicolumn{2}{|c|}{ Group F + L } & \multirow{2}{*}{ T-value } & \multirow{2}{*}{$\begin{array}{c}\text { P- } \\
\text { value }\end{array}$} \\
\hline & Mean & SD & Mean & SD & & \\
\hline \begin{tabular}{|l|} 
Time taken for complete loss \\
of cutaneous sensation at T10
\end{tabular} & 6.75 & 0.95 & 4.68 & 0.83 & 10.3854 & $0.0001^{*}$ \\
\hline \begin{tabular}{|c|} 
Time taken for 2 segment \\
regression of sensory blockade
\end{tabular} & 166.38 & 11.93 & 166.50 & 11.11 & -0.0485 & 0.9614 \\
\hline $\begin{array}{l}\text { Onset of motor blockade- } \\
\text { Bromage } 1\end{array}$ & 8.48 & 0.85 & 8.50 & 0.82 & -0.1344 & 0.8934 \\
\hline $\begin{array}{l}\text { Time for regression to } \\
\text { Bromage } 1\end{array}$ & 119.88 & 12.12 & 111.13 & 13.94 & 2.9968 & $0.0037^{*}$ \\
\hline Total duration of surgery & 94.88 & 21.59 & 87.75 & 19.15 & 1.5617 & 0.1224 \\
\hline
\end{tabular}




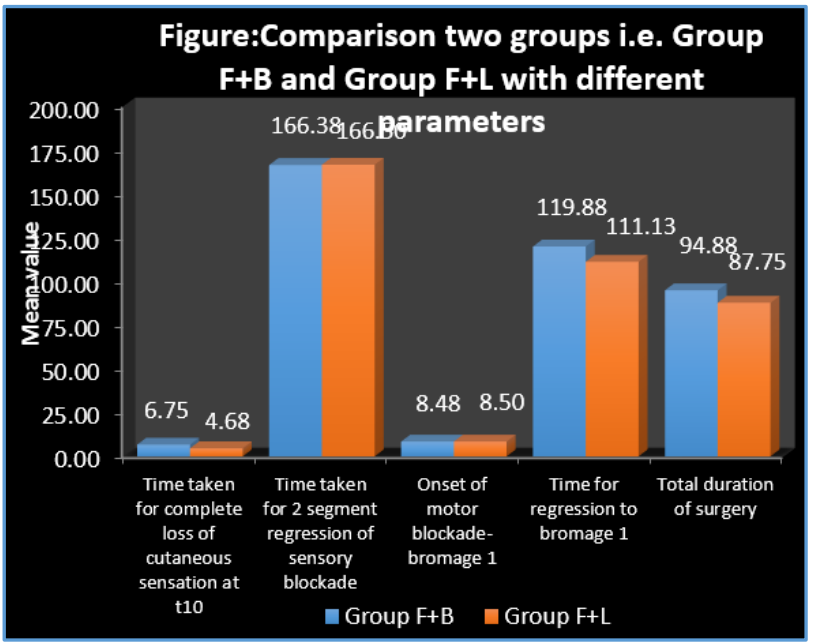

Chart 1. Comparison of Group F + B and F + L with different Parameters of Block Characteristics

\begin{tabular}{|c|c|c|c|c|c|c|}
\hline ASA & & & & & & \\
\hline Score 1 & 37 & 92.50 & 37 & 92.50 & 74 & 92.50 \\
\hline Score 2 & 3 & 7.50 & 3 & 7.50 & 6 & 7.50 \\
\hline \multicolumn{7}{|c|}{ Chi-square $=0.0000, p=1.0000$} \\
\hline \multicolumn{7}{|l|}{$\begin{array}{l}\text { Highest level of sensory } \\
\text { blockade }\end{array}$} \\
\hline T5 & 3 & 7.50 & 3 & 7.50 & 6 & 7.50 \\
\hline T6 & 27 & 67.50 & 25 & 62.50 & 52 & 65.00 \\
\hline T7 & 8 & 20.00 & 10 & 25.00 & 18 & 22.50 \\
\hline T8 & 2 & 5.00 & 2 & 5.00 & 4 & 5.00 \\
\hline \multicolumn{7}{|c|}{ Chi-square $=0.2993 \quad \mathrm{p}=0.9601$} \\
\hline \multicolumn{7}{|l|}{ Maximum Motor Blockade } \\
\hline Score 2 & 8 & 20.00 & 35 & 87.50 & 43 & 53.75 \\
\hline Score 3 & 32 & 80.00 & 5 & 12.50 & 37 & 46.25 \\
\hline \multicolumn{7}{|c|}{ Chi-square $=36.6561, p=0.00001^{*}$} \\
\hline Total & 40 & $\begin{array}{c}100.0 \\
0\end{array}$ & 40 & $\begin{array}{c}100.0 \\
0\end{array}$ & 80 & $\begin{array}{c}100.0 \\
0\end{array}$ \\
\hline Con & & up F+ & & $d F+1$ & & \\
\hline
\end{tabular}

\section{DISCUSSION}

The demographic profile of our patients was comparable with respect to mean age, body weight, body mass index, ASA grade and duration of surgery.

Epidural anaesthesia is an anaesthetic technique wherein the drug is injected in the epidural space either in lumbar or thoracic region of spinal cord. Caudal anaesthesia is also an epidural anaesthesia achieved through sacral hiatus. Neuraxial blockade procedure was first demonstrated by American Neurologist James Leonard Corning. ${ }^{1}$ Fidel Pages, a Spanish military surgeon developed single shot lumbar epidural anaesthesia. ${ }^{2}$ Achille Mario Dogliotti popularised the technique. In 1947, Manuel Martinez Curbelo described placement of lumbar epidural catheter. ${ }^{3}$ This anaesthetic technique is often used for both elective and emergency surgical procedure for various surgical conditions of abdomen, perineum lower limb and many obstetrics and gynaecological procedures. ${ }^{4}$

Many local anaesthetic drugs like xylocaine, bupivacaine and ropivacaine along with opioids like morphine and fentanyl are used to prolong anaesthetic effect through epidural space. 5 Other category of agents have been investigated for epidural administration such as alpha (2)adrenergic agonists, clonidine and dexmedetomidine. ${ }^{6}$ They are being used increasingly as adjuvants to local anaesthetics and opioids. Ketamine and neostigmine, the more recently studied drugs for epidural use are still under investigation and are not part of routine clinical practice. ${ }^{7}$

These drugs act through various sites ${ }^{8}$ and blocks the influx of sodium ions into the cell, thus preventing generation of action potential difference. However, the combination drugs which act through different mechanisms showed to have additive effect like combining fentanyl and Bupivacaine. ${ }^{9}$ Fentanyl has low molecular weight, high potency and lipid soluble synthetic opioid, is a suitable analgesic drug which is in use for labour since many decades. ${ }^{10}$ The racemic Bupivacaine has significant side effects and these can be minimised by the use of levobupivacaine. The study done by Philip et al and others have confirmed it. 11

In our study, the observation done was in par with other reports. After ruling out contraindication, ${ }^{11}$ calculated dose of fentanyl and bupivacaine was used as anaesthetic agent. We conducted a study on comparison of $0.5 \%$ isobaric bupivacaine and $0.5 \%$ isobaric levobupivacaine with fentanyl as a common adjuvant in epidural for lower abdominal and lower limb surgeries. This study confirmed that levobupivacaine with fentanyl has a faster onset of sensory blockade when compared to bupivacaine with fentanyl. The maximum motor blockade and the duration of motor blockade is better with bupivacaine and fentanyl when compared to levobupivacaine and fentanyl.

Glaser et al $^{12}$ compared $17.5 \mathrm{mg}$ of $0.5 \%$ levobupivacaine and racemic bupivacaine for hip replacement, observing a substantial equality in the pharmacological and cardiovascular characteristics of these isomers. In one study, higher plasma concentrations of levobupivacaine was observed. The plasma concentration of free (Unbound) levobupivacaine is lower than that of bupivacaine racemate, because of greater protein binding of the levorotatory enantiomer. Levobupivacaine has less toxic effects on cardiovascular and the central nervous system, therefore it is an alternative choice.

Levobupivacaine can be a good alternative to bupivacaine, the faster onset of sensory blockade, the smaller rate of motor blockade and the trend towards a smaller duration of motor blockade shows an interesting and potentially useful difference.

The action was evaluated by use of Bromage scale as mentioned in the table. A special attention was given to monitor the side effects on various system and tabulated. It was observed that the desired anaesthetic effect with least side effect was observed by the use of levobupivacaine with fentanyl than with use of racemic Bupivacaine.

\section{CONCLUSION}

In our study, the observation done was in par with other reports. After ruling out contraindication, a calculated dose of fentanyl and Bupivacaine was used. We conducted a study on comparison of $0.5 \%$ isobaric bupivacaine and $0.5 \%$ levobupivacaine with fentanyl as a common adjuvant in epidural for lower abdominal and lower limb surgeries. This study confirmed that levobupivacaine with fentanyl has a faster onset of sensory blockade when compared to bupivacaine with fentanyl. The duration of sensory blockade is comparable for the two groups. The maximum motor 
blockade achieved and the duration of motor blockade is better with bupivacaine and fentanyl, whereas sensory blockade was better with levobupivacaine and fentanyl. It is a safe combination if patient has cardiac disease too.

\section{Limitations of the Study}

The limitation of this study is that it was conducted on patients of lower limb and lower abdominal surgeries (below T10). We were not able to include the patients of upper abdominal surgeries.

We could not assess pain, quality and effectiveness of analgesia post-operatively. We could also not compare the differences in the requirement of analgesic top-up for the two groups post-operatively.

\section{REFERENCES}

[1] Uzuner A, Saracoglu KT, Saracoglu A, et al. The comparative study of epidural levobupivacaine and bupivacaine in major abdominal surgeries. J Res Med Sci 2011;16(9):1159-67.

[2] Bhatt SH. Levobupivacaine. A stereo - selective amide local anaesthetic. J Pharm Soc Wiscon 2001;3:28-34.

[3] Chirocaine (levobupivacaine). Product information. Norwalk, Connecticut: Purdue Frederick 2000.

[4] Cox CR, Faccenda KA, Gilhooly C, et al. Extradural S(-)bupivacaine: comparison with racemic RSbupivacaine. Br J Anaesth 1998;80(3):289-93.
[5] De Jong RH. Local anesthetics: from cocaine to xylocaine. In: Local anesthetics. St. Louis, USA: MosbyYear Book Inc, 1994: p. 4-5.

[6] Robinson AP, Lyons GR, Wilson RC, et al. Levobupivacaine for epidural analgesia in labor: the sparing effect of epidural fentanyl. Anesth Analg 2001;92(2):410-4.

[7] Simpson D, Curran MP, Oldfield V, et al. Ropivacaine a review of its use in regional anaesthesia and acute pain management. Drugs 2005;65(18):2675-717.

[8] Collins VJ. Spinal Anaesthesia - principles. Principles of Anesthesiology. $3^{\text {rd }}$ edn. Philadelphia: Lea Febiger 1993:1445-97.

[9] Ellis H, Feldman S, Griffiths WH. The vertebral canal and its contents. Anatomy for Anaesthetists. $8^{\text {th }}$ edn. Oxford: Blackwell Publishing Ltd., 2004: p. 104-5.

[10] Roger WS. Skeletal system - axial skeleton. Gray's Anatomy. Edinburgh: ELBS/Churchill Livingstone 1995: p. 510-46.

[11] Phillip BO, Nicholos GM, Soren BJ. Neural blockade in clinical anesthesia and pain medicine. $4^{\text {th }}$ edn. Philadelphia: Lippincott - Raven 2009.

[12] Fyneface-Ogan S. Anatomy and clinical importance of the epidural space. Epidural Analgesia - Current Views and 2012. 